\title{
Trying to Eat an Elephant (Again): Opportunities and Challenges in International Cooperative Approaches of the Paris Agreement
}

\author{
Rishikesh Ram Bhandary*
}

This article discusses the key design features of the international cooperative approaches in the Paris Agreement. The primary tension that animates the design elements of Article 6 is the need to build on the diversity of national approaches to climate change policy while ensuring environmental integrity, facilitation of implementation, and contribution to overall ambition. If designed carefully, Article 6 provisions can drive cost-effective mitigation, expand the scope of regulated emissions, and breathe new life into reducing emissions from deforestation, forest degradation, and the conservation and enhancement of carbon stock $(R E D D+)$. As countries already have some experience with the Kyoto Protocol's market mechanisms, various voluntary carbon offset programs, and internationally supported mitigation actions, countries have an opportunity to incorporate the learning into the implementation modalities of the Paris Agreement so that the international cooperative approaches can ensure environmental integrity, increase global ambition, and serve as a driver for implementation.

\section{Introduction}

The Paris Agreement has a set of tools to encourage countries to meet their commitments and increase ambition. Provisions in Article 6 refer to international cooperative approaches and include both market and non-market approaches. These instruments bear strong resemblances to the carbon offset and trading provisions of the Kyoto Protocol. This article focuses on two elements of the Article 6 package: Article 6.2 -internationally transferred mitigation outcomes - and Article 6.4 - the mechanism to promote mitigation of greenhouse gases and further sustainable development referred to in Article 6.4.

Article 6.2 displays the overriding logic of the Paris Agreement - a bottom up process whereby those countries - or entities - wishing to participate in internationally transferred mitigation outcomes can do so. This bottom-up construction marks a major departure from what the Kyoto Protocol anticipated in its emissions trading system whereby trading would happen only amongst those that have binding, economy-wide emissions reductions commitments (QELROs). Furthermore, another key distinction between Paris Agreement Article 6.2 and Kyoto Protocol Arti- cle 17 , on international emissions trading, is the degree of centralized governance for each mechanism. Kyoto Protocol rules were highly institutionalized in their level of specificity, obligation, and delegation while Article 6.2 has a strong bottom-up flavor with parties continuing to debate the extent of centralized guidance that is necessary.

Under the Kyoto Protocol, the Clean Development Mechanism offered an opportunity for industrialized countries to obtain compliance-grade emissions credits (Certified Emissions Reductions) at a possibly lower cost than what the same mitigation amount would have cost in industrialized countries. For developing countries, the inflow of investment, technology and contributions to sustainable development was a welcome win. Given the universal nature of the Paris Agreement where a bifurcation in the form of the Kyoto Protocol does not exist, the scope of Article 6.4 is much broader. Any country can be the host of abate-

DOI: $10.21552 / \mathrm{cclr} / 2018 / 3 / 10$

* Rishikesh Ram Bhandary, Climate Policy Lab, The Fletcher Schoo of Law and Diplomacy. The author would like to thank Michael Mehling and the co-editors of this special issue for useful feedback. For Correspondence: <rishikesh.bhandary@tufts.edu> 
ment activities under Article 6 and any country or entity can use these outcomes towards its commitments.

The narrative around Article 6 also marks a shift from the compliance and cost-effectiveness frames of the Kyoto Protocol's flexibility mechanisms towards higher ambition. For example, Article 6.1 notes that parties may wish to use cooperative approaches 'to allow for higher ambition' and Article 6.4 (d) stip ulates that the mechanism is to 'deliver an overall mitigation in global emissions.' ${ }^{1}$ Unlike the Clean Development Mechanism which was expected to help Annex 1 parties in complying with their commitments, Article 6 offers an avenue to increase the aggregate global effort in reducing emissions. Therefore, the purpose of Article 6.4 is not simply to offset emissions but to obtain an actual deviation in global emissions. It is important to note that cost-effectiveness and ambition are naturally intricately linked. ${ }^{2}$ The availability of low cost mitigation options may create grounds for stronger climate action. The key point is that Article 6 stresses higher ambition, which lowcost mitigation options may help to facilitate.

On terminology, Article 6.2 of the Paris Agreement refers to the use of internationally transferred mitigation outcomes (ITMOs) towards nationally determined contributions. These mitigation outcomes are not exclusively emissions reductions and removals. As there is no agreed definition of ITMOs, parties have found the room to debate what the mitigation outcomes entail. While many parties leave open how the mitigation outcomes may be generated, a number of them call for the expression of those units in $\mathrm{CO}_{2}$

1 UNFCCC, 'The Paris Agreement' < http://unfccc.int/files/essential _background/convention/application/pdf/english_paris_agreement .pdf $>$ accessed 1 August 2018.

2 For example, Kyoto Protocol Art 12 (2).

3 Japan, 'Japan's Submission on SBSTA Item 10(a): Guidance on Cooperative Approaches Referred to in Article 6, Paragraph 2, of the Paris Agreement' <http://www4.unfccc.int/Submissions/Lists/ OSPSubmissionUpload/579_344_131516859040704385-Japan _Submission_6.2_20171002.pdf> accessed 1 August 2018.

4 Norway, 'Submission to SBSTA from Norway on Article 6 of the Paris Agreement' <http://www4.unfccc.int/Submissions/Lists/ OSPSubmissionUpload/854_345_131538265003351574-Article6 _Norway.docx.pdf> accessed 1 August 2018.

5 Given the lack of agreement on the name of the mechanism referred to in Art 6.4 of the Paris Agreement at the time of writing, I use the neutral term A6M

6 UNFCCC, 'Decision 1/CP.21, Adoption of the Paris Agreement' $<$ https://unfccc.int/resource/docs/2015/cop21/eng/10a01.pdf> accessed 1 August 2018.

7 UNFCCC, 'Decision 1/CMA.1 Matters Relating to the Implementation of the Paris Agreement' <https://unfccc.int/resource/docs/ 2016/cma1/eng/03a01.pdf\#page=2> accessed 1 August 2018. equivalents. For example, see submissions by Japan ${ }^{3}$ and Norway. ${ }^{4}$ The linkage of emissions trading regimes would simply be one example of the range of actions that would fall under Article. 6.2. This article refers to the mechanism established by the Paris Agreement in Article 6.4 as the Article 6 Mechanism (A6M). ${ }^{5}$ The Conference of the Meeting of the Parties to the Paris Agreement, CMA, refers to the supreme body of the Paris Agreement. 'Parties' refers to parties to the Paris Agreement. The Paris Rulebook negotiations refers to the Paris Agreement Work Program (PAWP) designed to operationalize the Paris Agreement, which is expected to be completed by 2018 .

This article highlights the key issues that parties have discussed in the negotiations on Article 6 in the context of the PAWP and complements them with insights from the academic literature which is largely based on the experience with the Kyoto Protocol's flexibility mechanisms. Elaboration of Article 6 is one element of a larger work program parties have undertaken to advance the implementation of the Paris Agreement. At COP21, parties delegated the responsibility to elaborate guidance for Article 6.2 and rules, modalities and procedures for Article 6.4 to the Subsidiary Body for Scientific and Technological Advice (SBSTA) for consideration and adoption by the CMA at its first session (paragraphs 37-38 of 1/CP.21). ${ }^{6}$ Parties adopted the PAWP at CMA1 in Marrakech with the intention of concluding its work by the third session of the CMA $(1-3)$ in $2018 .^{7}$

The next section (Section 2) discusses key issues for internationally transferred mitigation outcomes, followed by a section on the A6M (Section 3). Section 4 discusses cross-cutting issues including interlinkages between Article 6 and other parts of the Paris Agreement, including the debate on the eligibility of reducing emissions from deforestation and forest degradation including carbon stock enhancement, sustainable management of forests, and conservation (REDD+) under Article 6 provisions and linkages with the International Civil Aviation Organization's Carbon Offsetting and Reduction Scheme for International Aviation (CORSIA).

\section{Article 6.2: Internationally Transferred Mitigation Outcomes}

The scope of Article 6.2 includes the emerging patchwork of emissions trading regimes that have been 
launched in various jurisdictions. Article 6.2 provides a framework to recognize such cooperation and fosters a direct link with the Paris Agreement infrastructure, particularly on accounting, reporting, and objectives such as sustainable development and environmental integrity. Parties diverge on the extent to which the CMA needs to provide guidance under Article 6.2. For example, Article 6.2 could provide guidance on how to report ITMOs and allow for a periodic assessment of their use through various avenues such as technical expert reviews and the global stocktake. Article 6.2 uses the generic term of mitigation outcomes to include the vast range of potential forms of cooperation between parties and their resulting outcomes. Parties diverge on who defines what an ITMO is. Options include definition by CMA, an Article 6.2 body or by the participating parties themselves. In principle, as linkages can work across other emissions abatement policies such as carbon tax regimes or non-carbon policies, for example renewable energy capacity targets, the range of units is large. ${ }^{8}$ Similarly, they disagree about the scope of the guidance. Some parties would prefer the guidance cover the entire lifecycle of ITMOs - creation, transfer, acquisition, and use - while others prefer limiting it only to the use of ITMOs towards NDCs. Furthermore, parties have debated the basis for corresponding adjustments. The bases identified in the text include budget-based, emissions-based, buffer-registry-based, and emissions reductionsbased. $^{9}$

Article 6.2 represents both a concession in the Paris Agreement that parties cooperate to mitigate greenhouse gas emissions outside the UNFCCC process and an acceptance of the regime's role in steering such approaches. The debate on the extent of CMA guidance that is needed for Article 6.2 is a disagreement on how strong the glue should be to knit these cooperative approaches together. Discussions in the negotiations have focused on two particular roles of Article 6.2: accounting guidance, and overall governance. Accounting is bottom-up for $\mathrm{Ar}-$ ticle 6.2 as parties are asked to engage in robust accounting that is 'consistent with' guidance that is supplied by the CMA.

Guidance on robust accounting, in the context of NDCs, will also be made operational under Article 13 (transparency framework). In this regard, parties have debated the appropriate vehicle for reporting ITMOs and views remain diverged on whether par- ties should use the modalities, procedures and guidelines under Article 13 or ones specific to Article 6.2. How parties are using Article 6.2 provisions to 'promote sustainable development and ensure environmental integrity and transparency, including in governance' however requires guidance to make these terms operational. Parties disagree on allowing parties to judge for themselves whether the ITMOs satisfy environmental integrity and sustainable development criteria, that they define on their own, and on the nature of the review process that would examine conformity with Article 6.2 guidance. Total silence from the CMA on these issues however may lead to situations where the negative impacts of ITMOs are so obvious that they necessitate a response. For example, ITMOs may create perverse incentives to increase the production of certain gases, as experience with HFCs under the CDM shows. Without adequately specified guidance on how the CMA will respond to such cases, the CMA's actions may seem arbitrary. As a result, some have argued for detailed guidance to foster predictability and confidence in Article 6.2-based actions.

Different jurisdictions moving at different speeds will entail price arbitrage opportunities. The danger with this, of course, is that while some jurisdictions tighten their caps stringently, others may lack the incentives and the political will to do so. Weaker caps will mean more opportunities to sell the cheaper credits to jurisdictions with tighter caps. Such situations invite a regulatory role for the CMA, however, those who advocate for a strong role for the CMA rarely go to the logical extreme and argue for an international regulatory body or an international carbon bank that could help cope with regulatory and liquidity problems that they fear.

\section{Article 6.4}

The mechanism established in Article $6.4(\mathrm{~A} 6 \mathrm{M})$ is the Paris Agreement's response to the Clean Devel-

8 Gilbert E Metcalf and David Weisbach, 'Linking Policies When Tastes Differ: Global Climate Policy in a Heterogeneous World' (2012) 6 Review of Environmental Economics and Policy 110.

9 UNFCCC, 'Paris Agreement Work Program Compilation Text' $<$ https://unfccc.int/sites/default/files/resource/Latest\%20PAWP \%20documents_9Sep.pdf $>$ accessed 1 August 2018. 
opment Mechanism and Joint Implementation of the Kyoto Protocol. Similar to the CDM and JI, the A6M's purpose is to incentivize mitigation of greenhouse gas emissions in a manner that supports sustainable development. Acquiring parties can use the emissions reductions generated through the implementation A6M activities towards their nationally determined contributions. Article 6.4 demands a stronger role from the CMA as the A6M is established under its auspices and bears the mandate to appoint a supervisory body. Unlike authorization by participating parties, Article 6.4 requires the engagement of this supervisory body in A6M related actions.

The scope of the mechanism is to promote the mitigation of greenhouse gas emissions as well as sustainable development. ${ }^{10}$ Such a firm link between greenhouse gas emissions reductions and sustainable development was also prevalent in the CDM and JI.$^{11}$ Yet, the record of CDM in promoting sustainable development and technology transfer is modest .$^{12}$ Furthermore, given that countries decided for themselves whether CDM activities contributed to sustainable development or not, systematic analysis of the impact of CDM projects and programs on sustainable development difficult. In the context of $\mathrm{Ar}-$ ticle 6.4, a number of countries have continued to argue that sustainable development is a national pre-

10 Art 6.4 notes that the mechanism will 'contribute to the mitigation of greenhouse gas emissions and support sustainable development' (emphasis author's).

11 Jørgen Fenhann and Frederik Staun, 'An Analysis of Key Issues in the Clean Development Mechanism Based on the UNEP Risoe Clean Development Mechanism Pipeline' (2010) 1 Carbon Management 65; Karen Holm Olsen and Jørgen Fenhann, 'Sustainable Development Benefits of Clean Development Mechanism Projects: A New Methodology for Sustainability Assessment Based on Text Analysis of the Project Design Documents Submitted for Validation' (2008) 36 Energy Policy 2773.

12 Stephen Seres, Erik Haites and Kevin Murphy, 'Analysis of Technology Transfer in CDM Projects: An Update' (2009) 37 Energy Policy 4919; Randall Spalding-Fecher and others, 'Assessing the Impact of the Clean Development Mechanism' (CDM Policy Dialogue 2012) A Report Commissioned by the High-Level Panel on the CDM Policy Dialogue; A Dechezleprêtre, M Glachant and Y Meniere, 'Technology Transfer by CDM Projects: A Comparison of Brazil, China, India and Mexico' (2009) 37 Energy Policy 703.

13 Govinda R Timilsina and others, 'Clean Development Mechanism Potential and Challenges in Sub-Saharan Africa' (2010) 15 Mitigation and Adaptation Strategies for Global Change 93.

14 Brazil, 'Views of Brazil on the Process Related to the Rules, Modalities and Procedures for the Mechanism Established by Article 6 Paragraph 4 of the Paris Agreement' <http://www4 unfccc.int/Submissions/Lists/OSPSubmissionUpload/73 345 131520606207054109-BRAZIL \%20-\%20Article\%206.4 \%20FINAL.pdf $>$ accessed 1 August 2018. rogative and any multilateral guidance on this should be minimal. Partly in reaction to such proposals of complete national determination, others have pointed to the multilaterally negotiated Sustainable Development Goals as offering a framework to examine the impacts of A6M activities. Arguably, a framing of A6M around the SDGs would also make the mechanism appealing to a broader set of actors. For example, a biodiversity frame or a poverty alleviation frame may be far more attractive to some than a carbon-centric one. While such calls for coherence may be most feasible at operational levels, such as project design, the SDGs and the Paris Agreement are distinct processes that pose different reporting obligations on parties. Similarly, the potential impact of A6M projects and programs on social and environmental dimensions has provided an entry point for those seeking to operationalize human rights in the context of the Paris Agreement.

Experience with the Clean Development Mechanism has underscored the importance of capacity building to enable the participation of countries. Similarly, another learning is the need to take into account diverse methodologies that take into account different contexts. ${ }^{13}$ The distribution of CDM projects has been skewed towards major emitters like China and India. While such a distribution is not surprising given the sheer availability opportunities for emissions reductions and the manner in which those governments facilitated CDM projects, geographic balance adds legitimacy and fosters long-term robustness of Article 6.4.

One of the most controversial issues in the negotiations of Article 6.4 has been the applicability of corresponding adjustments. While the text of the decision adopting the Paris Agreement in paragraph 37 mentions corresponding adjustment in the context of avoiding double counting transfers under Article 6.2, some parties have taken the lack of explicit mention of corresponding adjustments in Article 6.4 to imply that corresponding adjustments are not relevant for Article 6.4. The debate between parties mostly relates to when corresponding adjustments would take place rather than if. Brazil disputes the applicability of corresponding adjustments at the initial transfer of units from the A6M issuance registry to the national account and calls for corresponding adjustments to apply only when the acquiring party transfers the unit to a third party. ${ }^{14}$ In the latter case, Article 6.2 guidance would apply. Brazil's legal argu- 
ment is that Article 6.4 (c) allows host parties to benefit from mitigation activities as well and that a corresponding adjustment would nullify the benefits if not outright penalize their participation. ${ }^{15}$ Under this model, as corresponding adjustments would not apply when non-party stakeholders acquire units issued by the governing body of the A6M, it substantially incentivizes their participation in the A6M. While not all parties agree with this interpretation, they have extensively discussed this proposal in the negotiations.

Also akin to the Kyoto Protocol, the Paris Agreement makes a provision for a share of proceeds from the A6M to be used to support adaptation in countries that are 'particularly vulnerable' to the impacts of climate change. While the Kyoto Protocol's proceeds were designated to the Adaptation Fund, the Paris Agreement does not specify the destination of the proceeds. Some parties have also argued that a share of proceeds should be levied to Article 6.2 transactions as well. ${ }^{16}$ The question of who will manage the share of proceeds arrives at a time when countries have been debating the modalities for the Green Climate Fund's replenishment. As parties have decided that the Adaptation Fund may serve the Paris Agreement as well, it is also a contender. While there are concerns about the volatility of transactions, a revenue stream generated by the share of proceeds is attractive because it does not come with the conventional programming restrictions that grant or loan contributions to climate funds come with.

How parties make operational the concept of overall mitigation is also another salient issue. The supervisory body of the A6M has a responsibility to 'deliver an overall mitigation in global emissions' (Paragraph 4(d) Arti- cle 6). This formulation is a negotiated compromise between those parties that wanted the mechanism to 'enhance' mitigation and others who simply wanted the A6M to help meet existing NDC goals. Proposals to foster overall mitigation range from discounting or canceling a fraction of emissions reductions generated to the application of conservative baselines.

As most developing countries do not have economy wide targets, additionality has to be made operational in the context of sectors covered and uncovered by their NDCs. Paragraph $38(\mathrm{~d})$ of $1 / \mathrm{CP}_{21}$ notes 'reductions in emissions that are additional to any that would otherwise occur. ${ }^{17}$ Such a characteriza- tion of additionality is straightforward for uncapped sectors and conditional targets. For countries that do not have economy wide emissions targets, an important consideration is how A6M will affect the incentives to eventually broaden the scope of their NDCs (as Article 4.4 encourages parties to do so) instead of creating perverse incentives that would inhibit expansion.

As parties bring to life the A6M, they also have the task of how to handle CDM and JI in the Paris era. They need to address the pipeline that already exists under the CDM and JI and activities that will continue to generate emissions reductions beyond 2020 . The positions of parties range from a wholesale transfer of CDM/JI pipeline and projects under execution over to the Article 6 while others want to screen the projects to ensure that they fit the Article 6 criteria for eligibility. The overarching debate has been around ensuring environmental integrity of the Article 6 mechanism while at the same time being able to communicate positive signals to the investors about the desire to engage with them.

\section{Strategic issues}

The elements of Article 6 have natural interlinkages with other elements of the Paris Agreement. The risk that negotiators face is an evolution of the Article 6 elements in a direction that is decoupled from the rest of the Paris Agreement infrastructure. For example, without adequate and conscious efforts to link Article 6.2 with other parts of the Paris Agreement, ranging from the global stocktake to NDC guidance and accounting issues, ITMOs may have little bearing on the overall performance of the Paris regime. At the same time, the presence of these interlinkages also means that Article 6 can serve as a motor that helps to propel the Paris Agreement forward. Figure

15 Apart from the legal argument, Brazil has also made technical and environmental arguments. Please see Brazil's submissions for details <http://www4.unfccc.int/Submissions/Lists/ OSPSubmissionUpload/73_345_131520606207054109-BRAZIL $\% 20-\% 20$ Article\%206.4\%20FINAL.pdf $>$ accessed 1 August 2018.

16 AOSIS, 'Submission to the Articles 6.2 and 6.4 of the Paris Agreement by the Republic of Maldives on Behalf of the Alliance of Small Island States' <http://aosis.org/wp-content/uploads/2017/ 05/AOSIS_Submission_Art-6-2-and-6-4-of-PA.27.04.2017.FINAL _.pdf> accessed 1 August 2018.

17 UNFCCC, 'Decision 1/CP.21, Adoption of the Paris Agreement' (n 6) 


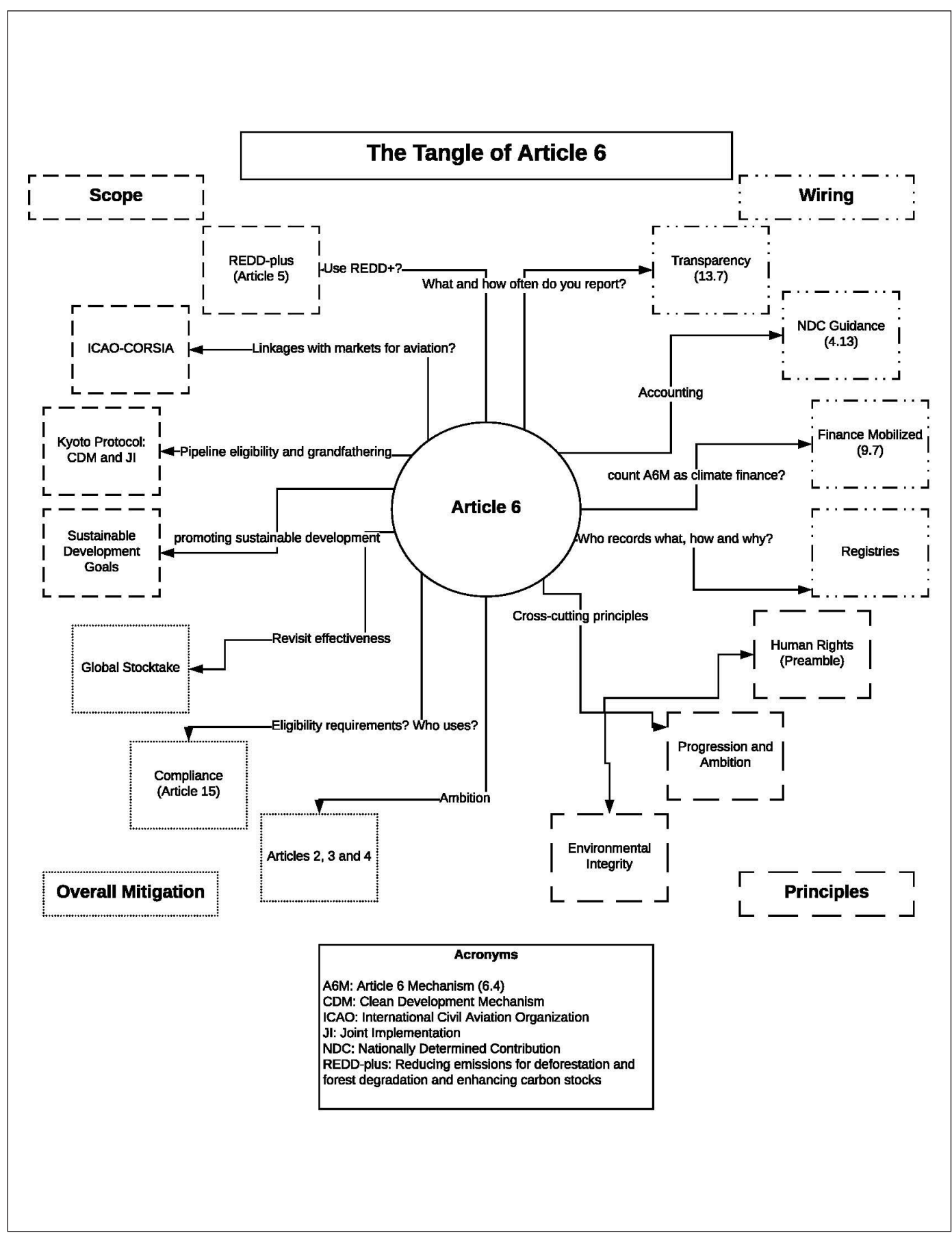

Figure 1: Article 6 and its interlinkages.

1 maps out some these linkages but it is not meant to be comprehensive.

The feedback between Article 6 and the rest of the Paris Agreement can work in at least three salient ways. First, Article 6 provisions can provide incentives for parties to improve the quality of information they submit as higher quality information will have lower uncertainty bands, thereby creating the 
opportunity for more payments for the same emissions reductions. Discussions on the transparency framework have remained stuck on how to operationalize differentiation for different sets of countries, however incentives for better quality information would offer a resolution. Ultimately, the climate regime will need the most accurate data available from all countries. Second, Article 6.4 can be an important hook for non-state action. UNFCCC's engagement with non-state actors can expand from registering commitments to undertaking commitments that can be verified under UNFCCC parameters. Third, Article 6 provides an opportunity for the UNFCCC to bring coherence to the bilateral and plurilateral forms of cooperation that exist and, as discussed below, sectors such as aviation.

\section{REDD - One Major Opportunity}

A key point of contention amongst parties has been on the eligibility of reduced emissions from deforestation and forest degradation and carbon stock enhancement (REDD+) under Article 6 provisions. Brazil, the most ardent opponent of the eligibility of REDD+ activities under Article 6, has long maintained a position that opposes viewing REDD+ through the prism of project-level interventions and carbon markets. Brazil has argued that REDD+ financing has already been resolved under the Warsaw Framework, where REDD+ is implemented at the national level and subnational interventions are only 'interim' measures. ${ }^{18}$ Brazil believes discussing REDD+ in the context of Article 6 would invite a wholesale re-litigation of the debate about the most appropriate scale of intervention for REDD+. Proponents of REDD+ activities under Article 6, however, do not view Article 6 as precluding any sector. Indeed, the language contained in Articles 6.2 and 6.4 is inclusive of all relevant sectors. If REDD+ credits are to be counted as ITMOs, they would also be subject to the same criteria. ${ }^{19}$ The challenge for negotiators, therefore, lies in investigating the existing Warsaw Framework on REDD+ and ensuring that it adequately addresses the four elements (promote sustainable development, ensure environmental integrity and transparency, and robust accounting) that Article 6.2 singles out.

Furthermore, the UNFCCC also has in its hands an opportunity to improve coherence with ICAO's efforts to reduce aviation-related emissions. ICAO has resolved to pursue to a carbon neutral growth path by holding emissions to 2020 levels, and it expects to use a collection of market-based and nonmarket based measures to achieve this goal. ICAO established the Carbon Offsetting and Reduction Scheme for International Aviation (CORSIA) to implement this goal. ICAO Assembly Resolution A39-3 (paragraph 20) has asked the ICAO Council to take into account developments under Paris Agreement Article $6 .^{20}$ Similarly, paragraph 21 of A39-3 notes that emissions units generated via UNFCCC mechanisms, including the Paris Agreement, are permissible under CORSIA provided that they conform with the technical criteria set. ${ }^{21}$ From this language it is clear that a broad range of emissions reductions achieved under the parameters of Article 6 would be eligible for use. If parties decide to explicitly bar REDD+ under Article 6, it is still likely that emissions reductions achieved via REDD programs and funds such as the Forest Carbon Partnership Facility, Forest Investment Program, and UN REDD would be eligible for ICAO-related commitments. To ensure completeness of emissions reporting, the transparency framework of the UNFCCC can require parties to report on such transactions irrespective of the exact means by which they address REDD-Article 6 linkages.

With ICAO's invitation, negotiators have two related opportunities. They can take the step forward to improve coherence with ICAO, a body that is regulating emissions using, in part, UNFCCC regulated sectors. Further, even the most ardent opponents of allowing REDD+ activities under Article 6 may find that it is far more practical to retain the governance of the financial aspects of REDD+ under UNFCCC auspices rather than the numerous non-UNFCCC ini-

18 Brazil, 'Views of Brazil on the Process Related to the Rules, Modalities and Procedures for the Mechanism Established by Article 6, Paragraph 4, of the Paris Agreement' <http://www4 .unfccc.int/Submissions/Lists/OSPSubmissionUpload/525_270 _131198656711178821-BRAZIL\%20-\%20Article\%206.4 \%20final.pdf> accessed 5 August 2018.

19 Art 6.2 notes the need for ITMOs to 'promote sustainable development and ensure environmental integrity and transparency, including in governance' and be undertaken with 'robust accounting ... consistent with guidance' adopted by the CMA.

20 ICAO, 'Resolution A39-3' <https://www.icao.int/environmental -protection/Documents/Resolution_A39_3.pdf $>$ accessed 5 August 2018.

21 ibid. 
tiatives that are implementing REDD+ programs and projects on their own.

\section{Conclusion}

Negotiators have an opportunity to learn from the experience of the flexibility mechanisms under the Kyoto Protocol and numerous initiatives outside of the UNFCCC process ranging from national emissions trading programs, their links with other jurisdictions, performance based payments for REDD+, joint crediting mechanisms and more. Based on the discussions above, there are three central concerns that animate the negotiations: the level of international oversight that parties want especially given the bottom-up features of the Paris Agreement; ensuring environmental integrity while accommodating the diversity of national efforts; and ensuring that Arti- cle 6 drives forward ambition in a manner that facilitates both host and acquiring parties to meet their NDC obligations.

In the Paris Rulebook negotiations, discussions on Article 6 have been contentious. A number of parties have pushed for balanced progress across all three elements of Article 6. This political push brushes against the different levels of conceptual maturity of the three elements and the extent of engagement needed by the CMA. Similarly, many developing countries also view Article 6 as a major bargaining chip that they can use in the negotiations with industrialized countries and groups such as the EU. Progress on Article 6, therefore, will be linked to how other parts of the Paris Rulebook talks move forward. Negotiators will have to choose the appropriate level of specificity in the decisions they adopt, knowing well that they will have opportunities to fine tune rules as they move forward. 